\title{
Effect of Scutellariae Radix Extract on the High Glucose-Induced Apoptosis in Cultured Vascular Endothelial Cells
}

\author{
Kwang Sik SuH, ${ }^{a}$ Yeon Ho NAM, ${ }^{a}$ Young Min AhN, ${ }^{b, c}$ Nam Jae KIM, ${ }^{d}$ Cheol Young PARK, ${ }^{e}$ \\ Gwanpyo KoH, ${ }^{a}$ Seungjoon OH, ${ }^{a}$ Jeong Taek Woo, ${ }^{a}$ Sung Woon KIM, ${ }^{a}$ Jin Woo KIm, ${ }^{a, d}$ and \\ Young Seol $\mathrm{KIM}^{*, a, c}$ \\ ${ }^{a}$ Department of Endocrinology \& Metabolism, Research Institute of Endocrinology, Kyung Hee University School of \\ Medicine; ${ }^{b}$ Department of Internal Medicine, Kyung Hee University School of Oriental Medicine; ${ }^{c}$ East-West Medical \\ Center, Kyung Hee University Hospital; ${ }^{d}$ Pharmacological Division, East-West Medical Research Institute, Kyung Hee \\ University; \#1 Hoigi-dong, Dondaemoon-ku, Seoul 130-702, Korea: and ${ }^{e}$ Department of Internal Medicine, College of \\ Medicine, Hallym University, Hallym Sacred Heart Hospital; \#896, Pyungchon-dong, Dongan-gu, Anyang, Kyunggi \\ 431-070, Korea. Received June 2, 2003; accepted July 18, 2003
}

\begin{abstract}
Endothelial cell apoptosis has been postulated as the initial trigger of the progression of microvascular disease in patients with diabetes mellitus. To investigate the role of Scutellariae radix extract, we examined its effect on the endothelial cell proliferation using the $\left[{ }^{3} \mathrm{H}\right]$-thymidine incorporation method. Scutellariae radix extract significantly stimulated endothelial cell proliferation in a dose-dependent manner. We focused on the protective action of Scutellariae radix extract on the endothelial cell apoptosis induced by high glucose concentrations. Determination of endothelial cell apoptosis was performed using DNA gel electrophoresis, terminal deoxynuclotidyl transferase-mediated dUTP nick end-labeling (TUNEL) assay, and an ELISA kit. Exposure of vascular endothelial cell to high glucose $(16.7 \mathrm{~mm})$ for $72 \mathrm{~h}$ resulted in a significant increase in apoptosis, compared with the normal glucose concentrations $(5.5 \mathrm{~mm})$. Scutellariae radix extract inhibited high glucose-induced endothelial cell apoptosis. This result suggests that Scutellariae radix extract may contribute to antiapoptotic action against vascular endothelial cells, resulting in a beneficial effect in preventing diabetes-associated microvascular complications.
\end{abstract}

Key words apoptosis; Scutellariae radix; endothelial cell; hyperglycemia; cell proliferation

Hyperglycemia plays an important role in the development of microvascular complications in diabetes mellitus. ${ }^{1)}$ Endothelial cells are considered candidates involved in the pathogenesis of diabetic vascular complications. It has been reported that endothelial cells cultured at high glucose concentrations show a slower rate of proliferation ${ }^{2,3)}$ and prolonged cell cycle, ${ }^{4}$ which is reversed by antioxidants. ${ }^{5)}$ In addition, high glucose concentrations trigger apoptosis in cultured endothelial cells. ${ }^{6-10)}$ Accelerated endothelial cell apoptosis is an important event in the process of diabetes-associated microvascular complications. Thus prevention of high glucose-induced endothelial cell apoptosis may have important implications for pharmacologic attempts to prevent these complications.

Studies have indicated that apoptosis can be induced by oxidative stress, ${ }^{6,7,10)}$ which is reversed by antioxidants. A thiol-containing antioxidant, $N$-acetyl-L-cysteine (NAC) prevents the decrease in intracellular glutathione (GSH) content and decreases both reactive oxygen species (ROS) generation and the number of cells committed to apoptosis in high glucose-induced human aortic endothelial cells (HAECs). $\left.{ }^{6}\right)$ The conditionally semiessential amino acid taurine attenuates hyperglycemia-induced human umbilical vein endothelial cell apoptosis through ROS inhibition and $[\mathrm{Ca}(2+)](\mathrm{i})$ stabilization. $^{\text {) }}$

Several Chinese herbal complexes that contain Scutellariae radix have been reported to have various beneficial biological activities. ${ }^{11-14)}$ Recent evidence shows that Scutellariae radix has beneficial properties, including antioxidative, antitumor, and anticonvulsant effects. ${ }^{15-17)}$ In addition, it has been demonstrated that the flavonoids isolated from Scutellariae radix inhibit adhesion molecules and plasminogen activator inhibitor-1 (PAI-1) production induced by thrombin, the thrombin receptor agonist peptide, and cytokines in cultured human umbilical endothelial cells. ${ }^{18-20)}$ These findings suggest that Scutellariae radix has a beneficial role in the regulation of endothelial cells. However, little is known about the effect of Scutellariae radix on apoptosis in endothelial cells. In this study, we hypothesized that Scutellariae radix extract may have a protective effect against high glucose-induced apoptosis in cultured endothelial cells.

\section{MATERIALS AND METHODS}

Plant Materials The roots of Scutellaria baicalensis (Labiaceae) were collected from Young-Am country, Korea. A voucher specimen (KHUVPO1064) is deposited in the East-West Medical Research Institute, Kyung-Hee University, Seoul, Korea. Dried roots of $S$. baicalensis $(1 \mathrm{~kg})$ were refluxed with $80 \%$ ethanol $(3 \times 3 \mathrm{l})$ for $2 \mathrm{~h}$. This extract was filtered and evaporated in a rotary vacuum evaporator and then finally lyophilized with a freezing dryer. The dry weight of the extract was $320 \mathrm{~g}$ (yield $32.0 \%$ ). To standardize the quality of extracts of $S$. baicalensis used in experiments, baicalin was quantitatively assayed according to the previous method. ${ }^{21)}$ The content of baicalin in extracts was $17.2 \%$. The extract was dissolved in dimethyl sulfoxide (DMSO) and diluted at the appropriate concentrations with the respective culture medium (final DMSO concentration was $0.05 \%$ $(\mathrm{v} / \mathrm{v}))$.

Cell Culture The bovine pulmonary artery endothelial cell line was provided by the American Type Culture Collection (Rockville, MD, U.S.A.). Cells were cultured in medium 199 (M199, Sigma, St. Louis, MO, U.S.A.) supplemented 
with $20 \%$ fetal bovine serum (FBS, Hyclone Corp., UT, U.S.A.), penicillin $100 \mu \mathrm{U} / \mathrm{ml}$, and streptomycin $100 \mu \mathrm{g} / \mathrm{ml}$ (Gibco BRL Co., U.S.A.). The cultures were maintained at $37^{\circ} \mathrm{C}$ in a humidified $5 \% \mathrm{CO}_{2}$ atmosphere and subcultured by trypsinization with $0.05 \%$ trypsin- $0.02 \%$ EDTA in $\mathrm{Ca}^{2+}$, $\mathrm{Mg}^{2+}$-free phosphate-buffered saline (DPBS, Gibco BRL Co., U.S.A.) when confluent monolayers were reached.

Assessment of Cell Proliferation Cell proliferation was determined by $\left[{ }^{3} \mathrm{H}\right]$-thymidine incorporation. Endothelial cells were seeded in 24-well culture plates (Falcon, Becton Dickinson, NJ, U.S.A.) at a density of $2 \times 10^{4}$ cells. After the cells were cultured in M199 supplemented with $20 \%$ FBS for $48 \mathrm{~h}$, the medium was replaced with fresh medium containing $0.3 \%$ bovine serum albumin (BSA, Sigma, St. Louis, MO, U.S.A.) in the presence or absence of Scutellariae radix extract $(0.001-0.1 \mathrm{mg} / \mathrm{ml})$ and incubated for $72 \mathrm{~h}$. For thymidine incorporation, the cells were labeled with $1 \mu \mathrm{Ci}$ of $\left[{ }^{3} \mathrm{H}\right]$-methyl thymidine (Amersham, Arlington Heights, IL, U.S.A.) for the last $6 \mathrm{~h}$ of incubation, and then were rinsed twice with DPBS and 10\% trichloroacetic acid (Sigma). Finally, the cells were dissolved in $2 \mathrm{~m}$ perchloric acid $(500 \mu \mathrm{l})$ (Sigma). Radioactivity was determined by $\beta$-scintillation counting (LS 3000, Beckman, U.S.A.).

Analysis of Apoptosis. DNA Gel Electrophoresis Cells were seeded at a density of $1 \times 10^{6}$ cells/dish in $100-\mathrm{mm}$ tissue culture dishes. After the cells were cultured in M199 supplemented with $20 \%$ FBS for $48 \mathrm{~h}$, cells were treated with medium containing $0.3 \%$ BSA with high glucose $(16.7 \mathrm{~mm})$ in the presence or absence of Scutellariae radix extract (final concentration $0.1 \mathrm{mg} / \mathrm{ml}$ ) for $72 \mathrm{~h}$. To demonstrate the formation of oligonucleosome-sized DNA fragments during apoptosis, we used the ApopLadder EX ${ }^{\mathrm{TM}}$ kit (Takara Shuzo Co., Japan). DNA pellets were solubilized in Tris-EDTA buffer (10 mm Tris- $\mathrm{HCl}$ [pH 8.0]; 1 mm EDTA). DNA fragments were analyzed on a $1.5 \%$ agarose gel electrophoresis and were visualized with ethidium bromide $(0.1 \mu \mathrm{g} / \mathrm{ml})$.

Terminal Deoxynucleotidyl Transferase-Mediated dUTP Nick End-Labeling Cells were cultured at a density of $1 \times 10^{4} /$ well on Lab-Tek chamber slides (Nunc, Copenhagen, Denmark). After the cells were cultured in M199 supplemented with $20 \%$ FBS for $48 \mathrm{~h}$, cells were treated with medium containing $0.3 \%$ BSA with high glucose $(16.7 \mathrm{~mm})$ in the presence or absence of Scutellariae radix extract (final concentration $0.1 \mathrm{mg} / \mathrm{ml}$ ) for $72 \mathrm{~h}$. In situ apoptosis detection kit (Takara Shuzo) was employed to assess apoptosis using the terminal deoxynucleotidyl transferase-mediated dUTP nick end-labeling (TUNEL) method. Apoptotic cells were fixed in $4 \%$ paraformaldehyde for $10 \mathrm{~min}$, washed in $10 \mathrm{~mm}$ Tris- $\mathrm{HCl}, \mathrm{pH} 8.0$, and then permeabilized in $0.1 \%$ Triton $\mathrm{X}$ 100, $\mathrm{pH}$ 8.0. Apoptotic cells were detected by labeling free 3'-OH DNA ends with fluorescein-labeled dUTP, using enzyme terminal deoxynucleotidyl transferase (TdT). Cells were subsequently exposed to peroxidase-labeled anti-fluorescein antibody. Cells were incubated with diaminobenzidine at room temperature for $15 \mathrm{~min}$, counterstained with $3 \%$ methyl green, and examined under light microscopy (Olympus, Japan). The total number of apoptotic cells in each slide was summed and expressed as a percentage of the total cell number.

Cell Death ELISA A cell death ELISA kit (Roche Molecular Biochemicals, Mannheim, Germany), which quantita- tively detects cytosolic histone-associated DNA fragments, was employed to assess apoptosis in cells. DNA fragments were measured according to the procedures described in the kit. Briefly, cells were seeded at a density of $2 \times 10^{4}$ cells in 24-well culture plates. The culture conditions were the same as those described in the TUNEL assay. After incubation, the cells were lysed, and intact nuclei were pelleted by centrifugation. An aliquot of the supernatant was used as the antigen source in a sandwich ELISA with a primary anti-histone monoclonal antibody coated to the streptoavidin-coated well of a microtiter plate. Subsequently, a second anti-DNA monoclonal antibody was coupled to peroxidase. The amount of nucleosomes was quantified based on the peroxidase retained in the immunocomplex. Peroxidase was determined photometrically at $405 \mathrm{~nm}$ with 2,2'-azino-di[3-ethylbenzthiazolinsulfonate] (ABTS) as the substrate.

Statistical Analysis Experiments were carried out in six cultures and expressed as mean \pm S.D. Differences between the means were calculated using one-way analysis of variance (ANOVA) with a subsequent Duncan's multiple range test $(p<0.05)$. The analysis was performed using SAS statistical software (SAS Inc., NC, U.S.A.).

\section{RESULTS AND DISCUSSION}

We initially examined the effect of Scutellariae radix extract on endothelial cell proliferation using the $\left[{ }^{3} \mathrm{H}\right]$-thymidine incorporation method. When cells were treated with Scutellariae radix extract $(0.001-0.1 \mathrm{mg} / \mathrm{ml})$ in a normal glucose concentration $(5.5 \mathrm{~mm})$, DNA synthesis was increased in a dose-dependent manner (Fig. 1). This finding may support the view that Scutellariae radix extract can stimulate proliferation of endothelial cells. Determination of endothelial cell apoptosis was performed using three independent methods (DNA gel electrophoresis, TUNEL assay, and ELISA kit). It is well established that endothelial cells cultured with high D-glucose, but not with an equimolar concentration of L-glucose or D-mannitol, results in a significant increase in apoptosis. ${ }^{6-10)}$ In the present study, the endothelial cells were exposed to high glucose concentration (M199 containing $16.7 \mathrm{~mm}$ glucose), which was chosen to match glucose concentrations prevalent in patients with diabetes whose

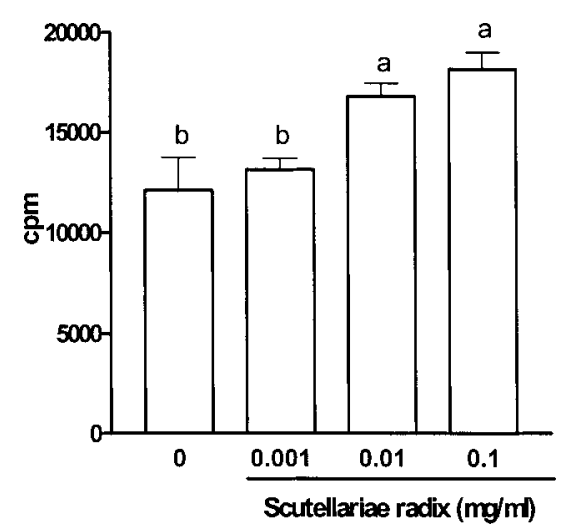

Fig. 1. Effects of Scutellariae Radix on the DNA Synthesis of Endothelial Cells Cultured in the Medium Containing 5.5 mm Glucose

Vascular endothelial cells were cultured with vehicle or various concentration of Scutellariae radix extract for $72 \mathrm{~h}$. Data shown are mean \pm S.D., expressed as cpm. Groups with different letters at the top of the bars are significantly different from each other by analysis of variance $(p<0.05)$. 
glucose levels are not controlled.

We first confirmed apoptosis using DNA gel electrophoresis in cells treated with high glucose $(16.7 \mathrm{~mm})$ for $72 \mathrm{~h}$. No degradation was observed when the cells were cultured in medium containing 20\% FBS. However, DNA degradation was increased following the removal of FBS. To optimize our ability to detect DNA fragmentation, apoptosis was induced by the removal of FBS and cultured in high glucose concentrations in the presence or absence of Scutellariae radix extract $(0.1 \mathrm{mg} / \mathrm{ml})$. DNA extracted from the high glucose-pretreated cells showed extensive nuclear fragmentation, with DNA being degraded to multiples of an 180-bp subunit, whereas less degradation was observed when the cells were treated with Scitellariae radix extract (Fig. 2). The fragmented DNA was also detected histochemically by terminal labeling. Exposure of vascular endothelial cells to high glucose concentrations for $72 \mathrm{~h}$ resulted in a significant increase in TUNEL-positive cells when compared with normal glucose. Scutellariae radix at a concentration of $0.1 \mathrm{mg} / \mathrm{ml}$ inhibited the increase in TUNEL-positive cells caused by high glucose (Fig. 3a). We also determined the number of dead cells using trypan blue staining (data not shown). Although the absolute number of dead cells detected by trypan blue staining and the number of TUNEL-positive cells differed, comparable results were obtained using both methods (data not shown). Similar results were also obtained with the ELISA kit that quantitatively detects DNA fragmentation. High glucose caused an increase in DNA fragmentation when compared with normal glucose. Scutellariae radix extract $(0.1 \mathrm{mg} / \mathrm{ml})$ significantly inhibited high glucose-induced apoptosis (Fig. 3b). However, there was no effect on the apoptosis of endothelial cells treated with normal glucose in the presence of Scutellariae radix extract. Similarly, it has been reported that taurine significantly prevented high glucose-induced endothelial cell apoptosis, whereas taurine had no effect on the apoptosis found in the normal glucosetreated group. ${ }^{7)}$

It has been reported that endothelial cells cultured in high glucose concentrations have a slower rate of proliferation ${ }^{2,3}$ ) and prolonged the cell cycle. ${ }^{4)}$ The antioxidants reverted endothelial cells to almost normal growth, showing that high glucose may delay endothelial cell replication through the generation of free radicals. ${ }^{5-7)}$ Studies have indicated that oxidative stress triggers apoptosis in high glucose-induced endothelial cells, which is reversed by antioxidants. ${ }^{6,7,10)} \mathrm{Re}-$ cent evidence has shown that Scutellariae radix has beneficial properties, including antioxidative effects. ${ }^{15-17)}$ However, to the best of our knowledge, the effect of Scutellariae radix extract on apoptosis in high glucose-induced endothelial cells has not been reported. In the present study, Scutellariae radix extract inhibited high glucose-induced endothelial cell apoptosis. This suggests that Scutellariae radix extract may prolong the life span and thereby instigate an increase in the number of endothelial cells. The various pharmacologic effects of Scutellariae radix extract and its active compounds (baicalein, baicalin, and wogonin) have been demonstrated in a cultured human bladder cancer cell line ${ }^{16)}$ and human umbilical vein endothelial cells. ${ }^{18-20)}$ It has recently been shown that baicalein selectively inhibits the nitric oxide-dependent apoptotic pathway of activated brain microglial cells by suppressing cytotoxic nitric oxide production. ${ }^{22)}$ However, the

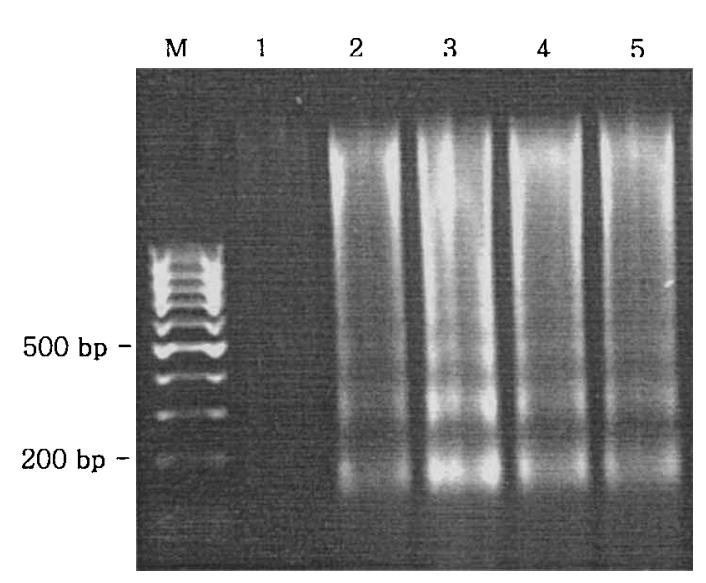

Fig. 2. Gel Electrophoresis for Detection of Endothelial Cell DNA Fragmentation

Cells were incubated with normal glucose $(5.5 \mathrm{~mm})$, high glucose $(16.7 \mathrm{~mm})$, and high glucose + Scutellariae radix extract (SR) for $72 \mathrm{~h}$. DNA gel electrophoresis was performed as described in Materials and Methods. Lane M, DNA size marker; lane 1, $5.5 \mathrm{~mm}$ glucose $+10 \%$ FBS; lane 2, $5.5 \mathrm{~mm}$ glucose; lane 3, $16.7 \mathrm{~mm}$ glucose; lane 4, 5, $16.7 \mathrm{~mm}$ glucose $+\mathrm{SR}$.

(A)

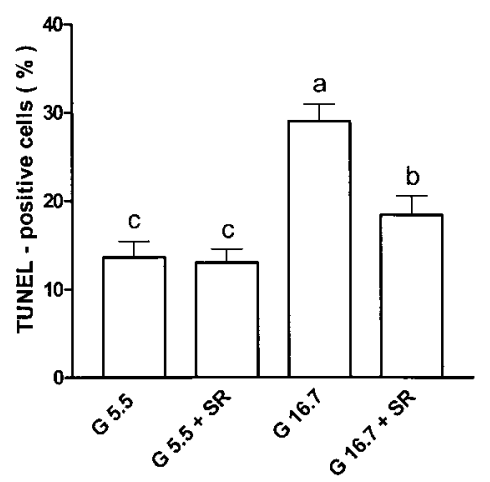

(B)

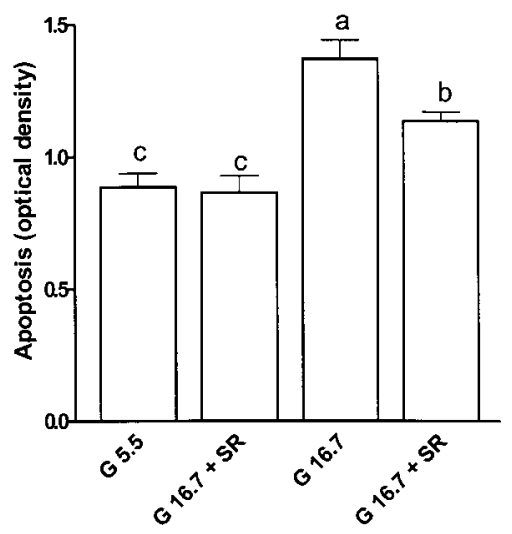

Fig. 3. Scutellariae Radix Extract Inhibits High Glucose-Induced Endothelial Cell Apoptosis

Vascular endothelial cells were cultured with $5.5 \mathrm{~mm}$ glucose (G 5.5), and $16.7 \mathrm{~mm}$ glucose (G 16.7) in the presence or absence of Scutellariae radix extract (SR) for $72 \mathrm{~h}$. Endothelial cell apoptosis was assessed using the TUNEL method (A) and ELISA kit (B) as described in Materials and Methods. Data shown are mean \pm S.D. Groups with different letters at the top of the bars are significantly different from each other by analysis of variance $(p<0.05)$.

antiapoptotic action of individual compounds of Scutellariae radix was not identified in the present study. Further studies are needed to investigate which ingredient primarily con- 
tributes to the antiapoptitic effect of Scutellariae radix and to identify the underlying mechanism responsible for this action on the high glucose-induced apoptosis in endothelial cells.

As opposed to the antiapoptotic effect on vascular endothelial cells, it has been reported that an herbal complex containing Scutellariae radix has an antitumor effect on other cells. ${ }^{11)}$ Of particular interest is the recent demonstration that Scutellariae radix and its components have an antitumor effect on cultured bladder cancer cell lines. ${ }^{16)}$ The mechanisms through which Scutellariae radix extract exerts multidirectional action remain to be clarified.

In summary, the present results demonstrate that Scutellariae radix extract not only stimulates cell proliferation but also inhibits high glucose-induced apoptosis in vascular endothelial cells, which may be associated with the regulation of vascular endothelial cells. Thus Scutellariae radix may have beneficial effects in the treatment of diabetes-associated microvascular complications.

Acknowledgments This work was supported by a grant from the research program of Kyung Hee University Hospital. Kwang Sik Suh and Yeon Ho Nam contributed equally to this study.

\section{REFERENCES}

1) American Diabetes Association, Diabetes Care, 21, 2180-2184 (1998).

2) Doyle J. M., Smith R. M., Roth T. P., Horm. Metab. Res., 29, 43-45 (1997).

3) Rojas S., Rojas R., Lamperti L., Casanello P., Sobrevia L., Exp. Physiol., 88, 209-219 (2003).
4) Lorenzi M., Nordberg J. A., Toledo S., Diabetes, 36, 1261-1267 (1987).

5) Curcio F., Ceriello A., In Vitro Cell. Dev. Biol., 28A, 787-790 (1992).

6) Recchioni R., Marcheselli F., Moroni F., Pieri C., Metabolism, 51, $1384-1388$ (2002).

7) Wu Q. D, Wang J. H., Fennessy F., Redmond H. P., Bouchier-Hayes D., Am. J. Physiol., 277, C1229-C1238 (1999).

8) Chai W., Chen J., Wang H., Shen J., Ma L., Ma X., Chin. Med. J., 113, 903-906 (2000).

9) Ido Y., Carling D., Ruderman N., Diabetes, 51, 159-167 (2002).

10) Du X. L., Sui G. Z., Stockklauser-Farber K., Weiss J., Zink S., Schwippert B., Wu Q. X., Tschope D., Rosen P., Diabetologia, 41, 249-256 (1998).

11) Lian Z., Fujimoto J., Yokoyama Y., Niwa K., Tamaya T., Eur. J. Gynaecol. Oncol., 22, 347-349 ( 2001).

12) Sanae F., Komatsu Y., Chisaki K., Kido T., Ishige A., Hayashi H., Biol. Pharm. Bull., 24, 1137-1141 (2001).

13) Kase Y., Saitoh K., Makino B., Hashimoto K., Ishige A., Komatsu Y., Phytother. Res., 13, 468-473 (1999).

14) Kyo R., Nakahata N., Sakakibara I., Kubo M., Ohizumi Y., Biol. Pharm. Bull., 21, 1067-1071 (1998).

15) Nemoto Y., Satoh K., Toriizuka K., Hirai Y., Tobe T., Sakagami H., Nakashima H., Ida Y., In Vivo, 16, 327-332 (2002).

16) Ikemoto S., Sugimura K., Yoshida N., Yasumoto R., Wada S., Yamamoto K., Kishimoto T., Urology, 55, 951-955 (2000).

17) Wang H. H., Liano J. F., Chen C. F., J. Ethnopharmacol., 73, 185-190 (2000).

18) Kimura Y., Matsushita N., Yokoi-Hayashi K., Okuda H., Planta Med., 67, 331-334 (2001).

19) Kimura Y., Yokoi K., Matsushita N., Okuda H., J. Pharm. Pharmacol., 49, 816-822 (1997).

20) Kimura Y., Matsushita N., Okuda H., J. Ethnopharmacol., 57, 63-67 (1997).

21) Hayakawa J., Noda N., Yamada S., Mikami E., Uno K., Yakugaku Zasshi, 105, 996-1000 (1985).

22) Suk F., Lee H., Kang S. S., Cho G. J., Choi W. S., J. Pharmacol. Exp. Ther, 305, 638-645 (2003). 